\title{
STRATEGIES FOR IMPROVING COMPLEX CONSTRUCTION HEALTH AND SAFETY REGULATORY ENVIRONMENTS
}

\author{
Nnedinma Umeokafor ${ }^{1}$, Konstantinos Evangelinos ${ }^{2}$ and Abimbola Windapo ${ }^{3}$ \\ ${ }^{1}$ University of Greenwich, United Kingdom \\ ${ }^{1}$ Email:nnedinmaik@hotmail.com \\ ${ }^{2}$ Department of Environment,University of the Aegean, Greece \\ ${ }^{3}$ University of Cape Town, South Africa
}

In enhancing business and project performance, a robust H\&S regulatory system which is homogenous is one of the prerequisites, but developing countries (DCs) are lagging in this. Using Nigeria as a case study, the research developed strategies for improving the regulation of construction H\&S in a complex regulatory environment. Semi-structured intervews, analysled thematically, was adopted. The proposed H\&S improvement strategies include contextualised construction H\&S legislation that will enable the establishment of a homogenous but flexible regulatory system. This will be overseen by an independent National Construction H\&S regulator but with the controlled support of selected industry and social actors. The regulatory process will include persuasion (such as negotiation), punitive measures, education and awareness strategies. The proposed strategies also include that H\&S legislation should stipulate duties for clients, contractors and subcontractors including goal-based legislation with mainly absolute duties, and prescriptive legislation or guidance. This should not be misconstrued as oversimplifying complex phenomena. The study could help policymakers and H\&S experts in countries such as Nigeria develop strategies informed by realities of H\&S regulatory complexities, in increasing the chance of workability and acceptance of the strategies proposed by the regulated.

Keywords: Compliance, Construction Regulations, Construction Health and Safety, Developing countries, Productivity, Safety management strategies.

\section{INTRODUCTION}

The construction industry is known for it hazardous activities; its accident record is disproportionate to its workforce and other industries (International Labour Organisation 2018) and is the highest across other industries. For example, the provisional data of Health and Safety Executive ((HSE) 2018) for 2017/2018 shows that the construction industry of Britain has the highest level of fatal injury across all other industries, 38 fatal injuries and maintains an average of 39 fatal injuries from 2013/14-2017/18 (HSE 2018).

According to Manu et al. (2018), developing countries (DCs) have worse H\&S records. For instance, in Nigeria, Okoye (2018) reports a study of 236 construction workers of different trades in one of the 36 states of Nigeria, Anambra state, showing that the carpenters, masons, iron benders and steel fixers all have a very high-risk level of $13.7,13$, and 12.3 respectively. This was measured against the risk scale recommended by the Code of Practice on Workplace Safety and Health Risk Management (Workplace Safety and Health Council, 2011). The information outlined is indicative of the situation in Nigeria, as accidents are highly unreported (International Labour Organisation (ILO) 2017). Similarly, Manu et al. (2018) demonstrate that the construction industries in DCs such as Malaysia and Singapore 
record high fatal injuries and remains the highest among other sectors, also see Siew (2015). The current study aims to develop strategies for improving the regulation of construction H\&S in a complex regulatory environment such as Nigeria.

Pybus' (1996) evolution of safety culture model, which can be used in studying among many safety culture and safety management (see Finneran and Gibb 2013), is made up of three stages, traditional, transitional and innovative phases. The traditional phase is reactive and there is emphasise on individual control, attention to discipline, compliance and enforcement of laws and standards, with emphasis on acute effects of injury. While the measures can reduce accidents, they are not as effective as the transitional and innovative phases. The transitional phase is more proactive centering on considering hazards before they arise through ways such as employee training, and engineering control. The most proactive and effective is the innovative stage where there is attention to culture and motivational issues and H\&S is integrated in all business decisions while all efforts are made to eliminate the risks through approaches that include the use of technologies.

According to Finneran and Gibb (2013: 7), 'it is generally accepted that phases cannot be missed out - in other words, attention to rules, discipline and enforcement need to be embedded within organisations and individuals before much benefit will be gained by focussing on safe work procedures and, certainly, concentrating on behaviours without having the appropriate training and controls in place would be considered as inappropriate and ineffective'. In essence, the regulation and compliance with H\&S laws and standards are among the fundamentals and pillars for improving and ensuring sustainable H\&S. This does not only reinforce the significance of this study to Developing Countries (DCs), but also draws attention to an overlooked fundamental area for improving H\&S in some countries such as Nigeria (Umeokafor et al. 2018)

While some countries such as Britain have moved to the innovative phase (leaders), many countries including DCs are still in the traditional and/or transitional phases (Laggards) (Finneran and Gibb 2013). Regulatory and compliance related issues are reported in various DCs such as South Africa, Ghana and Nigeria (Abubakar 2016; Annan et al. 2015; Diugwu et al. 2012; Umeokafor et al. 2014; Windapo 2013; Zahoor et al. 2016). For example, according to Abubakar (2016), the H\&S regulatory systems of DCs are based on Distributed Occupational Safety and Health (DOSH) system. 'DOSH regulatory framework leverages on multiple and less coherent legal provisions dispersed in various related laws ... (while) the Consolidated OSH $(\mathrm{COSH})$ regulatory framework refers to a relatively harmonised regulatory and enforcement framework which comes with mandate expansion, enrichment of regulations, increased regulator powers, more budgetary allocations as well as enhanced executive and financial independence' (Abubakar 2016: 61-62). Implications of the DOSH include multiple regulatory actors and complex regulatory regimes.

Moreover, in the Nigerian construction industry, the regulatory system is poorly understood and unexamined. For example, authors such as Diugwu et al. (2012) and Idoro (2011) report the self-contribution of contractors in CH\&S through the adoption of CH\&S regulations from developed countries but compliance is at the discretion of the adopters, as they are not enforceable locally. Famuyiwa (2011) reports the 
contribution of local authorities in Lagos state in terms of H\&S regulation and Omeife and Windapo (2013) report the voluntary adoption of National Building Code of 2006 as it has not yet received legislative backing as at then. The regulatory authorities (such as Federal Ministry of Environment and National Environmental Standards and Regulations Enforcement Agency (NESREA)) whose activities cut across the construction industry are covered in detail in ILO (2017). The Minerals Oils (Safety) Regulations 1963 (as amended) and Petroleum Act (Laws of the Federation of Nigeria (LFN)) 2004 (as amended) cover the oil and gas industry in terms of H\&S and environment, by implication construction contractors working in the oil industry are bound by the law and regulatory activities. Similarly, the Employee Compensation Act 2010 implemented by the Nigeria Social Insurance Trust Fund Management Board also covers the construction industry. However, the construction industry has been reported as unregulated because its sites and activities are omitted in the Factories Act CAP F1, L.FN. 2004 definition of premises (Diugwu et al. 2012 and Idoro 2011), one of the main laws on OHS in Nigeria. Hence H\&S matters are addressed from that perspective. Drawing on the self-regulation concept in previous studies, for example, Bartle and Vass (2005), Gunningham (2011) and Gunningham and Rees (1997) the practices above show that the Nigerian construction industry is self-regulated in various ways. The regulatory regime is complex with multiple laws and regulatory actors, interests, structure, methodologies and implications for regulation.

Consequently, in reporting part of this extensive study that fills this vast gap in knowledge, this paper presents the strategies to improving the regulation of Construction H\&S (CH\&S) in complex regulatory environments based on empirical evidence from Nigeria. The objectives set are to: examine the CH\&S regulatory system in Nigeria; explore and explains strategies for improving the regulation of $\mathrm{CH} \& \mathrm{~S}$ in Nigeria; and explore and explain the possible roles of various parties in the strategies for improving the regulation of CH\&S in Nigeria. The study is important because it will help policymakers, academics, H\&S experts, contractors and other relevant stakeholders design effective strategies for improving the regulation of CH\&S. However, the proposed strategies should not be misconstrued as oversimplifying complex socio-legal and socio-technological phenomena.

\section{CONCEPTUAL FOUNDATION}

\section{Regulation including self-regulation}

Regulation can be fixed or flexible but the level of flexibility varies. Command-andcontrol regulation (which is fixed) is where the state solely and directly oversees the activities of organisations or industry by setting standards and controlling them with punitive measures (Gunningham and Rees 1997). In terms of achieving compliance with H\&S laws, it has underperformed (Aalders and Wilthagen 1997). Consequently, there has been a move to flexible options such as self-regulation where the regulated is involved in the regulatory process (Aalders and Wilthagen 1997; Fairman and Yapp 2005). Self-regulation varies from country-to-country and industry-to-industry hence there is no satisfactory definition (Gunningham and Rees 1997). In voluntary or pure self-regulation the standards are self-imposed and overseen (including controlled and monitored) by the regulated, for example industry or organsiation (Bartle and Vass 2005; Gunningham 2011; Gracia Martinez et al. 2007). Gracia Martinez et al. (2007) add co-regulation - a combination of private and public parties e.g. Government and 
the industry. Gunningham (2011) presents other types or level of self-regulation including mandatory full self-regulation where the government oversees the setting and enforcement of rules by organisation or industry.

In making self-regulation feasible and desirable (or moving beyond command-andcontrol regulation) Aalders and Wilthagen (1997) draw on the concept of 'reflexivity' developed by Teubner (1983) from responsive law, to argue and suggest 'reflexivity'-reflective administrative law. In this context, Aalders and Wilthagen (1997: 436) suggest that 'a mixture of legal and non-legal, public and private, strategies is necessary, such as: systems monitoring, intermediary structures and networks, corporate social responsibility, and market-oriented strategies'. Importantly, Aalders and Wilthagen (1997) advocate that the 'negotiating state' in adopting these strategies, alongside other parties, should learn to cope with issues not limited to third-party interests and access to information.

The flexibility in self-regulation enables the involvement of third parties of which one model is Tripartism. According to Ayres and Braithwaite (1991), this is underpinned by regulatory policy where Public Interest Groups (PIG) are involved in three ways. While their involvement is significant in the regulatory process, one implication of this is that the parties involved are the regulated, the regulator (who will self-regulate, - the self-regulator-) and the PIGs.

\section{Performance of self-regulation}

The British construction industry is self-regulated but with external involvement. For many years, it has maintained a better H\&S record than many other construction industries (see HSE 2018). In the US, a delegated industry CH\&S self-regulatory programme recorded success in the prevention of accident when compared to the traditional command-and-control regulatory system (Scharrer and Bogus 2011). Conversely, in the manufacturing industry of New Zealand, Walls and Dryson (2002) report a failed H\&S self-regulatory programme where, for example, only $8 \%$ of the sample provided adequate $H \& S$ training scheme.

\section{METHODOLOGY}

Semi-structured interviews were adopted in the study because of the research questions, aim and objectives of the study and that it focuses on complex social phenomena (Saunders et al. 2009). Qualitative methods excel in answering 'why', 'what' and 'how' research questions (Erikkson \& Kovalainen, 2008), the type of research questions in the current study. The research process relevant to this paper is graphically summarized in Figure 1.

\section{Data collection instrument}

Following a review of relevant literature and informal consultation with key informants in the Nigerian construction industry, the semi-structured interview guide was developed. It covered areas not limited to the profile of the organisations and the respondents and ways that $\mathrm{CH} \& \mathrm{~S}$ regulation can be improved and possible follow-up questions and prompts. The interview protocol refinement framework by CastilloMontoya (2016) was used to improve the interview guide. Made of four phases: the first phase of the framework-Ensured that the interview questions aligned with the research questions'; second phase-'constructing an inquiry-based conversation' 
including possible follow-up questions and prompts were considered and drafted; third phase-'receiving feedback on the interview protocol'; fourth phase-'piloting the interview protocol'.

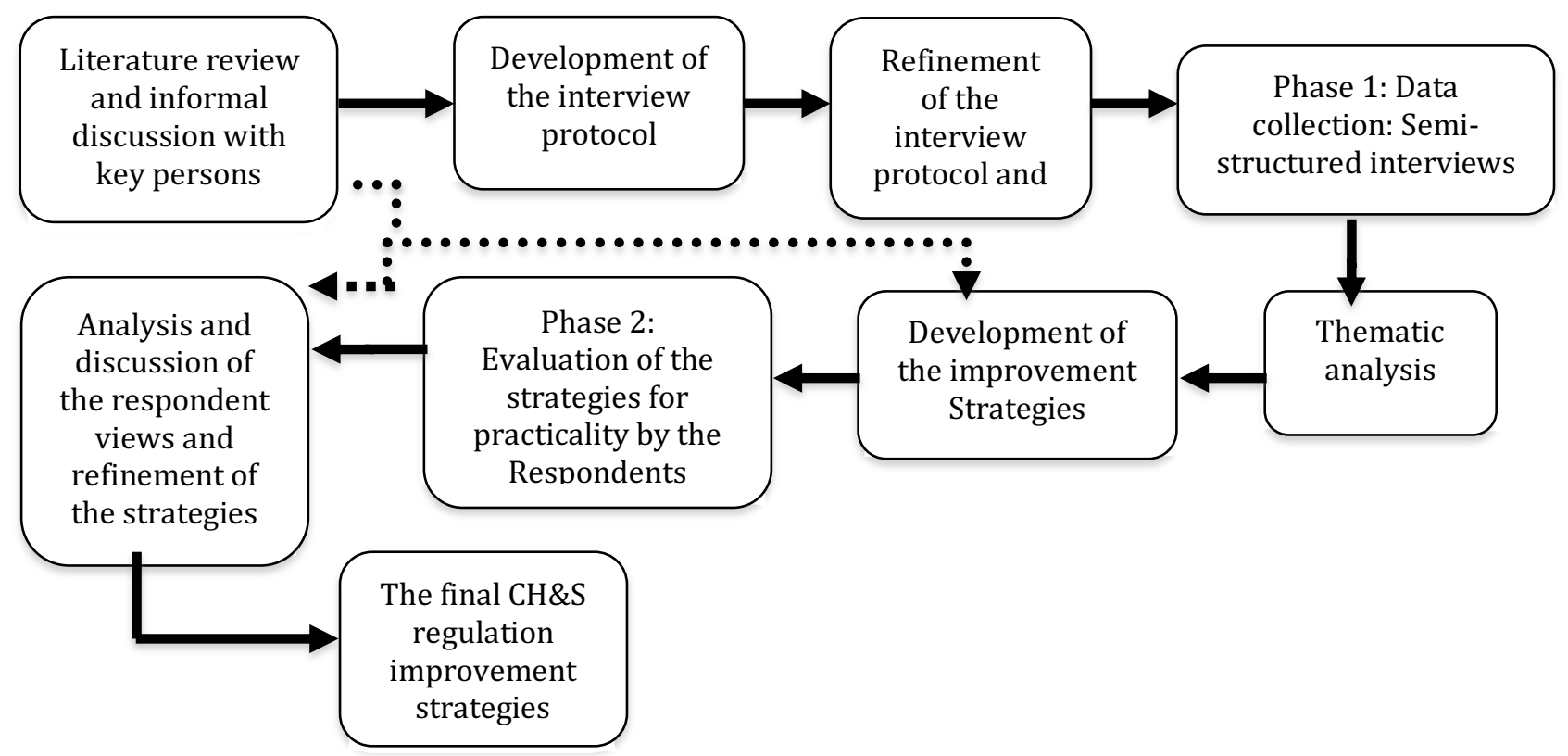

Figure 1: Research Process; Author's field work

Legend: Analysis link

Process link:

\section{Data collection}

Ethical approval was obtained from the University of Greenwich Research Ethics Committee. Figure 1 shows that the data collection was in two phases, the first phase, the main data collection and analysis; the second phase, the development of the improvement strategies, evaluation by respondents and analysis. Only the relevant parts of the research process are presented in this paper.

The respondents were sent introductory letters, covering an introduction to the research project, its aims, how the data will be used, anonymity, and the options of withdrawal from study and the interview. As at the time of collecting the data, there was no reliable or comprehensive list of contractors in Nigeria, following efforts made to obtain this from different sources. Hence a pilot study or preliminary survey was conducted. Authors such as Idoro (2011) conducted a preliminary study which was used as the population of the study. Drawing on the output of a pilot study to ascertain the population, a combined or mixed purposeful sampling, involving stratified purposeful sampling and snowballing sampling, were adopted. This was because of the context of the research and research questions (Palys 2008). The aim of the stratified purposeful sampling was to include the major variations in the population (Patton 1990). Accroding to Adami (2005) this is to present a full breadth of the population (population representation) and not for statistical generalisation. Hence, the strata were made up of the four categories of contractors, large contractors (LCs), medium-sized contractors (MCs), small-sized contractors (SCs) and micro-size 
contactors (MiCs) from the six geopolitical zones of Nigeria. The definition of the contractors is in line with Kheni (2008) where micro contractors employ below 10 employees, the small contractors have 10 to 29 employees, medium-sized contractors are made up of 30 to 199 employees and large contractors employ above 199 workers.

In line with Suri (2011), the snowballing sampling involved key informants who can provide credible information and recommend people who can do same. The key informants must meet the criterion of having direct or indirect association with the contractors in terms of safety, health and the environment. Those who are H\&S consultants must have worked or currently work for a construction contractor

Fifty-three interviews, face-to-face and telephonically, were conducted. However, only 46 interviews (from 31 contractors and 15 key informants) were used because of saturation. The interviews lasted for 65-117 minutes. The evaluation of the strategies for improving CH\&S regulation was done by eleven participants of which some of them were among the 53 participants. Where possible, the seven different probing techniques (Easter-Smith et al. 1991) were adopted. The techniques are not limited to confirming the responses of the interviewees by repeating them, directing the questions to expand or understand some points and asking the interviewees to expand on some points with examples or to explain how some thing happened. The lead author ensured that the questions were not confrontational, eye contact was maintained with the interviewees, and the face-to-face ones were in a conducive atmosphere. The interviews were recorded with the permission of the respondents and transcribed verbatim.

In evaluating the developed strategies for improving $\mathrm{CH} \& \mathrm{~S}$ regualtion for workability or practicality, it was sent to three academics and twelve professionals of which eleven responded. On receipt of the respondents' views on the workability, the framework of recommendations was revised. No actions were taken based on the three academic and eleven professional views of the strategies for improving $\mathrm{CH} \& \mathrm{~S}$ regulation because the suggestions were consistent with the framework; and no evidence that the suggestions were more workable or better than the strategies.

\section{Trustworthiness in the research}

In addition to refining the interview protocol to improve it, the following were also done to improve transparency, credibility, dependability, conformability and transferability in the research (Guba 1981; Lincoln and Guba 1985; Nowell et al. 2017). They include multiple triangulation (triangulation of persons, analytical triangulation and method triangulation), thick rich description, peer debriefing, addressing investigator effects and refinement of the interview protocol.

Triangulation is the use of different data collection techniques, data or data points to collaborate the findings in a study (Saunder et al. 2009). In the study, the triangulation of persons entailed using key informants and the four categories of contractors. The analytical triangulation meant a combination of analytical approaches (manual, computer assisted and constant comparison), which also formed the methods triangulation (Humble 2009). The computer aid was NVivo for Mac while the constant comparison involved within and between groups of analysis 'Constantly Self-regulating Contractors (CSRCs)', 'Non-Constantly Self-regulating Contractors (NCSRCs)' and 'Non Self-regulating Contractors (Non-SRCs)'. The analytical 
triangulation occurred in terms of convergence, dissonant, complementary, illumination and providing unique information (Sand and Roerstrier 2006).

As there is a risk of the investigators influencing the data (Umeokafor 2015), the following, were done. First, the expression of emotions by the investigator during the data collection was avoided. Second, the investigator debriefed the respondents, explaining that he is well aware of the happenings in the Nigerian construction industry, having worked there, hence they are free to share their experiences with him. This is because as the investigator is based in the UK (one of the countries with a good H\&S record), the respondents may be biased and provide incorrect information or only those that will impress the investigator. This peer debriefing may not eliminate bias and falsehood from the respondents, but just as one of the anonymous reviewers noted, it is a critical part of debriefing, contributory to conformability and credibility in the research. It can help readers make sense of the scene of the research setting, how this may bias the responses of the interviewees. Third, in line with Creswell and Miller (2000), the author's experiences, beliefs and perceptions with the potential to influence data collection and analysis were consciously acknowledged. The detailed methodology of this paper constitutes 'thick description' covering how and why events happened.

In line with Braun and Clarke (2006), Nowell et al. (2017) and one of the anonymous reviewers, trustworthiness in research can be demonstrated by 'mapping of the means of establishing trustworthiness to the actual six phases of analysis as described in Braun and Clarke (2006)'. Selected examples (not an exhaustive list) of this are covered in Table 1

Table 1: A summary of the mapping of the means of establishing trustworthiness in each phase of the thematic.

Source: Author's elaboration

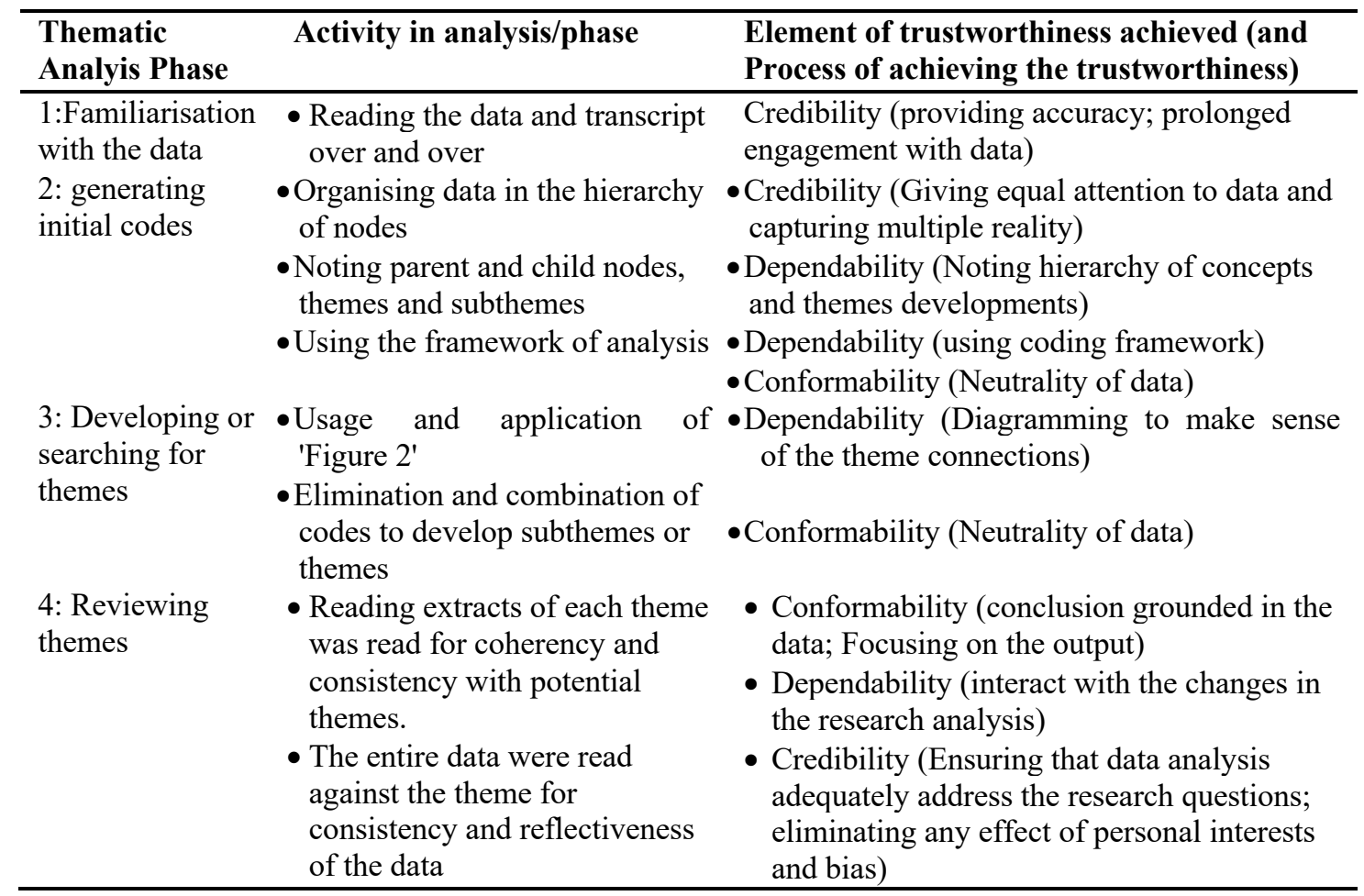




\begin{tabular}{|c|c|c|}
\hline $\begin{array}{l}\text { 5: Defining } \\
\text { and naming } \\
\text { themes }\end{array}$ & $\begin{array}{l}\text { - Changing and clarifying } \\
\text { themes and subtheme }\end{array}$ & $\begin{array}{l}\text { - Credibility (Giving equal attention to data } \\
\text { and capturing multiple reality; providing } \\
\text { accuracy) } \\
\text { - Dependability (Interact with the changes in } \\
\text { the research analysis) }\end{array}$ \\
\hline \multirow[t]{3}{*}{ 6: Writing up } & $\begin{array}{l}\text { - The research methodology } \\
\text { presented in detail. }\end{array}$ & $\begin{array}{l}\text { - Transferability (enables readers to make } \\
\text { informed conclusions) } \\
\text { - Dependability (enables repeating finding } \\
\text { with same subject and the same context) }\end{array}$ \\
\hline & •Using of direct quotes & - Credibility (providing accuracy) \\
\hline & $\begin{array}{l}\text { - Justifications of all the done in } \\
\text { the analysis }\end{array}$ & $\begin{array}{l}\text { - Dependability (Reporting reasons for } \\
\text { methodology and analytical process) }\end{array}$ \\
\hline
\end{tabular}

While conformability has been established in the analysis in Table 1, Guba and Lincoln (1989) supported by Nowell et al. (2017) argue that when transferability, credibility and dependability are achieved, conformability is established. Also, transferability is often left for the reader, the researcher or author can just enhance this by doing a lot already covered. If this is the case, it can be argued that this is established in Table 1.

\section{Data analysis}

The data collected were analysed thematically using the six-phases of analysis in Braun and Clarke (2006): 1) Familiarisation with the data, 2) generating initial codes, 3) Developing or searching for themes, 4) Reviewing themes, 5) Defining and naming themes, and 6) Writing up. The six phases are not linear hence flexible (Braun and Clarke 2006). The part of the extensive study reported in this paper, the CH\&S regulation improvement strategies was analysed inductively, where the coding process does not involve fitting the data to a pre-existing code frame. However, the output of the rest of the analysis of the extensive study (which was analysed using the hybrid (inductive approach and deductive) approach) contributed to the development of the framework in ways not limited to refuting and supporting points. Adopting inductive thematic analysis, and deductive thematic analysis are consistent with studies such as Braun and Clarke (2006) and hybrid thematic analysis (combination of both) consistent with studies such as Fereday and Muir-Cochrane (2006). Nevertheless, it is common that the investigators have ideas of possible initial codes in inductive analysis (cf. Strauss and Corbin 1990). In establishing saturation, the saturation grid by Brod et al. (2009) was adopted where, among many, during the interviews, a preliminary saturation grid was developed and refined during the data collection. Details of this can be found in (name withheld till after review)

For the 'Familiarisation with the data' phase, having transcribed the data verbatim, the lead author read the data many times to be immersed in it. According to MeroJaffe (2011), the verbatim transcription provided a valid and complete picture, which is similar to the interviews. Drawing on literature review, the contractors were then categorised into CSRCs, NCSRCs and Non-SRCs. This was to help improve the analysis.

The 'initial codes' phase involved systematically identifying and naming the key features of the data. Here, questions (for example, what is missing here, what message is being passed and what is happening here) were asked and the transcripts were read line-by-line, in line with Basit (2010). Commonly used words (are not limited to 'improving inspections', 'more enforcement' and 'effective regulator of H\&S') where 
also explored to suggest conceptual categories (Bowen 2008). It also involved the constant comparison of the analytical groups, CSRCs, NCSRCs, Non-SRCs and key informants. Manifest and latent meanings were considered here. To manage the data, they were coded to broad parent codes (Bowen 2008). The codes were organized and structured in hierarchy, parent (such as 'improving H\&S regulation' and 'outliners') and child nodes (not limited to 'penalities', 'increase fines', 'help contractors to comply', and 'work together'). NVivo for Mac was used for the analysis. Importantly, the field notes were also factored in the analysis. At this stage, the candidate themes became clearer (Braun and Clarke 2006).

Following this, the codes were arranged and themes and subthemes were searched and developed, Phase 3. This involved looking for the potential of combining codes to form themes and subthemes (Braun and Clarke 2006) with some features of NVivo for Mac such as 'text search quays'. However, coding disputes were resolved, relationship among codes were redefined and refined, resulting in the elimination and combination of codes where necessary, to develop themes or subthemes.

These were then refined in the next phase, 'Reviewing themes'. Here, the candidate theme were reviewed, some eliminated, merged and new ones formed. The level of consistency in the data, level of sufficiency and the strength of the manifest and latent meanings informed this. This entailed two sub-phases. For sub-phase 1, the extracts of each theme was read for coherency and consistency with potential themes. While some themes were adequate, some were merged to form richer themes or subthemes and then distilled; of course, this has already started in the previous phase. Then for sub-phase 2, the entire data were read against the theme for consistency and reflectiveness of the data; coding and refinement occurred until sufficient. The themes were then 'defined and named' or 'redefined and renamed' (Braun and Clarke 2006). Here, each theme was explored for their contribution to explaining and understanding the strategies or recommendations, coherency and consistency, interesting content and the story the theme was telling (Braun and Clarke 2006). The last phase was 'writing up' or reporting of the entire data, themes and subthemes to ensure that readers receive the messages it intends to pass, using quotations, tables and a diagram.

\section{Development of the improvement strategies}

In the development of the improvement strategies, the perceptions of the interviewees, and the findings of the literature review were used. They were then analysed and evaluated with strong reference to literature and the other findings of the extensive study (Name withheld till after review), for example the barriers and drivers to CH\&S regulation in Nigeria. The output of this was evaluated by 11 respondents for workability and is reported elsewhere in this paper.

\section{RESULTS}

\section{Overview of the profile of the respondents}

The 31 contracting firms were made up of: $10 \mathrm{CSRCs}$ (seven large, two mediumsized and one small-sized contractors) where seven were foreign and indigenous owned and three indigenous contractors; 14 NCSRCs (one large, six medium-sized, five small-sized and two micro-sized contractors), all indigenous owned; seven NonSRCs (one medium-sized, three small-sized and three micro-sized contractors), all indigenous owned. The 31 respondents from these contracting firms include 
owners/managers, H\&S managers, Project managers, Civil engineers, Quantity Surveyors, and Architects. Some respondents held more than one designation, for example, in being the owner/manager, one respondent was also a structural engineer. The scope of their experiences vary from Micro-sized firm to large contracting firms, oil and gas sector, banking projects including some that have worked in more than one of these. Their years of experience range from over 20 years to less than five years experience.

For the key informants' organisations - those with direct or indirect association or involvement in the construction industry or contractors -13 organisations participated including four $\mathrm{H} \& \mathrm{~S}$ consultancy firms, multinational structural consultancy firms, a regulatory body who oversees engineering practices in construction and, among many, investigate collapsed buildings, safety regulator in one of the 36 states and an insurance firm. The 15 key informants include clients, members of trade associations, a lecturer who is a quantity surveyor, a lawyer, and employees of regulatory bodies. Their years of experience range from less than five to over 28 years.

The respondents that evaluated the improvement strategies include two H\&S managers, one H\&S officer, a Civil Engineer, a Quantity surveyor, two buildiers, one project manager, an owner of a contracting company who is also an Architect and two academics from higher education institutions with Building Engineering and Quantity Surveying backgrounds. All of the evaluators have over six years of experience in the construction industry including the academics who have 15 and 25 years experience respectively. The contractors cover the six geopolitical zones and four categories of contractors.

\section{Respondents' recommendations for improving CH\&S}




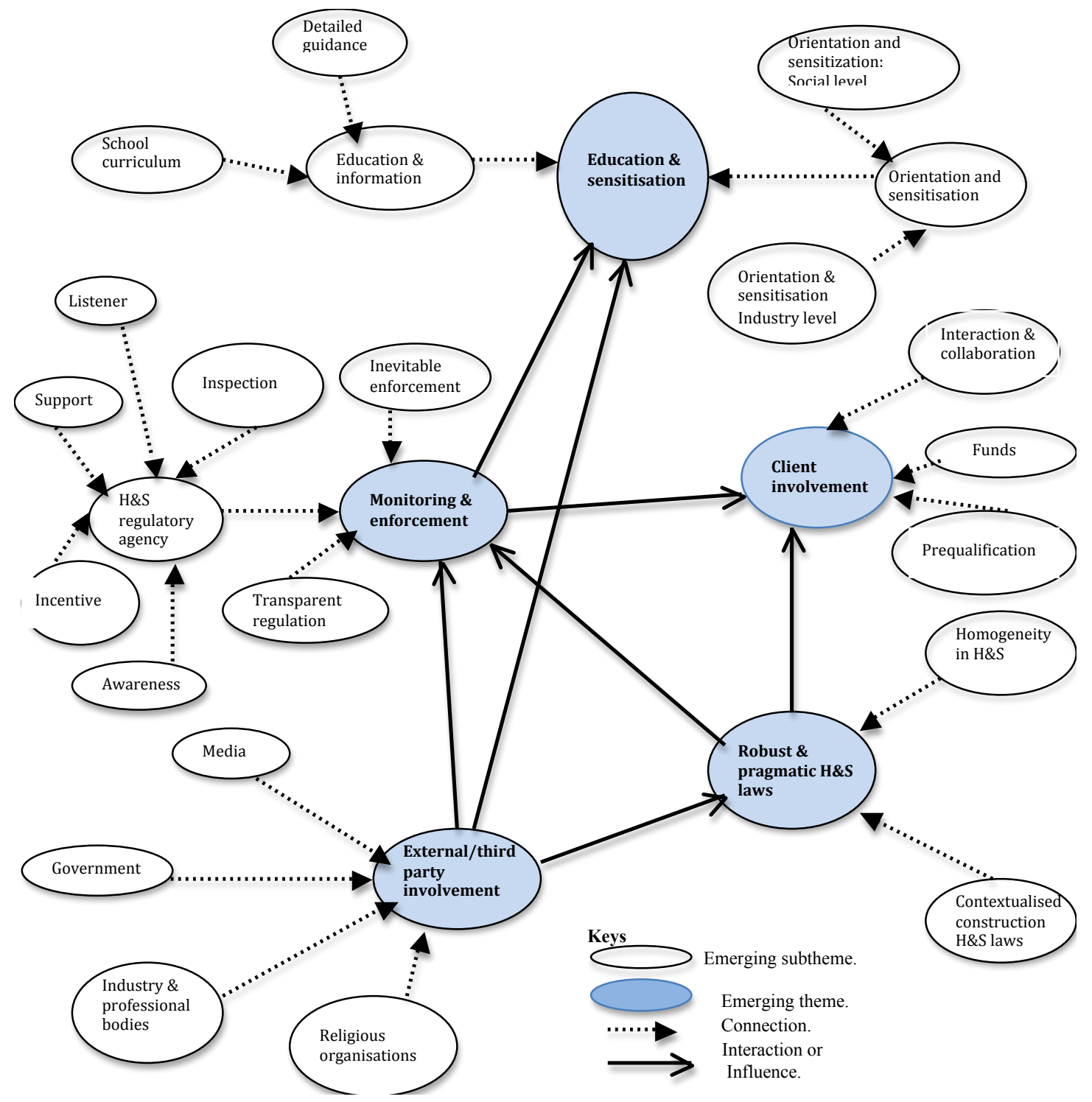

Figure 2: Graphic illustration of the summary of respondents recommendations for improving $\mathrm{CH} \& \mathrm{~S}$ regulation. Source (purposefully withheld till after review)

Figure 2 shows the graphic representation of the summary of respondents' views on CH\&S improvement ways and the interactions or influences among the themes. Among many, it shows that while contextulised H\&S laws and homogeneity in H\&S are needed for robust and pragmatic H\&S laws, the involvement of external actors are needed therein and in the monitoring and enforcement of the laws, education and sensitisation. The respondents recommend robust and pragmatic H\&S laws that will stipulate client involvement but based on a good understanding of the local context (Table 2). The involvement of other parties is also expected, for example industry association and the government (Table 2).

Table 2 provides details of the themes presented in Figure 1. It does not only cover what the proposed regulator is expected to do, but also how to improve compliance including self-policing. The Table indicates a high level of risk ownership by the respondents - while they want external involvement in various ways, they want to be involved in the regulatory process. Drawing on the conceptual foundation section, this 
is in line with self-regulation. By implication, there is an appetite for flexible regulation.

In terms of education and sensitization (Table 2), there was consensus among the respondents except the Non-SRCs that effective $\mathrm{CH} \& \mathrm{~S}$ regulation centres on educating the regulated on the benefits of compliance with $\mathrm{H} \& \mathrm{~S}$, a suggested responsibility for the H\&S regulator. This also centres on the long terms benefits. Some of the respondents suggested, stated or demonstrated the need for improved awareness of H\&S compliance and CH\&S responsibilities. Many NCSRCs, NonSRCs and Key informants expect that there should be adequate H\&S guidance to support regulation and compliance. One respondent stated:

It is true that there should be enforcement of the laws, but if we know what to do and the subcontractors understand the importance of compliance with $H \& S$, the regulator will spend the enforcement resources on other things. It is not possible that they will visit all the sites in the country. For example, the people that regulate the medicines that we take are not doing a good job because the awareness is low.

This was expanded and collaborated by the subthemes in the statutory client involvement (Table 2). These subthemes place responsibilities on the clients, that clients will support compliance, take on part of the enforcement responsibilities and collaborate with the regulator of H\&S in the enforcement and monitoring of CH\&S. For example a respondent was of the view that:

Clients should be able to do more such as working with the regulator of H\&S in many ways including reporting contractors that do not comply. However, this will be more effective if the client has the statutory responsibility to do such.

In other words, the respondents expect the clients, contractors and the regulator of H\&S to work hand-in-hand. The enforcement responsibilities tend to be proactive but also serves as a leverage for contractors. For example, the pre-assessment of contractors indicates contractors that are likely to comply with $H \& S$ hence support enforcement and monitoring and gives the contractors leverage in procurement so that next time they will comply. Those that do not comply will lose out.

Table 2: Summary of views of respondents on ways to improve CHSE regulation

\begin{tabular}{|c|c|c|}
\hline Themes & Subthemes & Evidence \\
\hline $\begin{array}{l}\text { Consolidated } \\
\text { Monitoring and } \\
\text { enforcement }\end{array}$ & $\begin{array}{l}\text { - H\&S regulatory } \\
\text { agency }\end{array}$ & $\begin{array}{l}\text { - Private, state and independent industry actors but state } \\
\text { empowered. } \\
\text { - Strict, 'hard' and frequent enforcement of laws } \\
\text { - Reputation management -naming and shaming of } \\
\text { contractors by the media } \\
\text { - Honesty in regulation } \\
\text { - Transparency in regulation including enforcement. } \\
\text { - Regulation that does not encourage or support corruption } \\
\text { - Auditing the regulatory activities of the H\&S regulator by } \\
\text { the media. } \\
\text { - Enforcement and monitoring by a national H\&S regulatory } \\
\text { and monitoring agency but independent. } \\
\text { - Statutory backing for a national regulator. The National } \\
\text { H\&S regulator to: support and guide contractors; create } \\
\text { awareness of H\&S in the industry; site inspection, provide }\end{array}$ \\
\hline
\end{tabular}




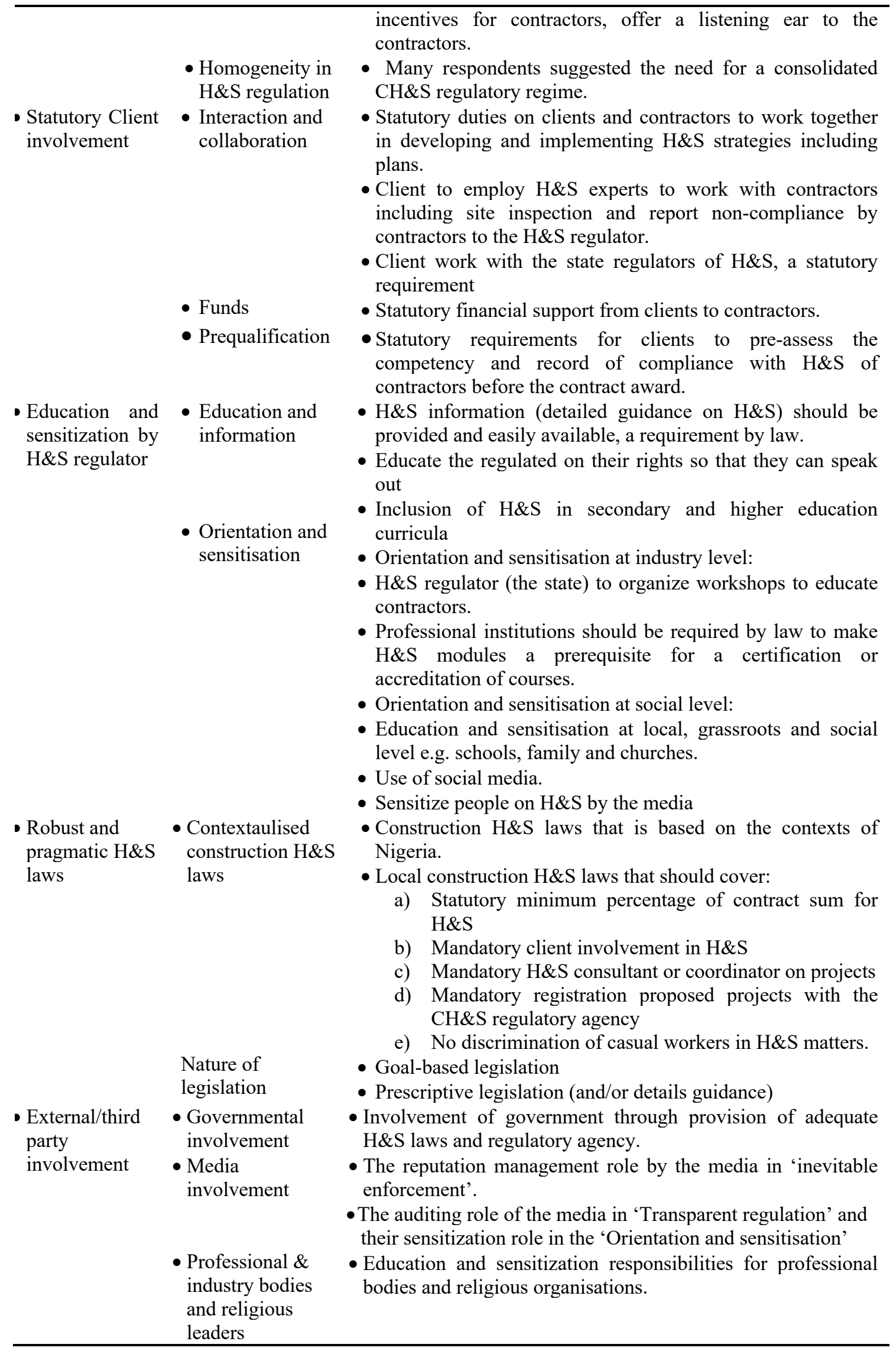

Table 2 shows the strong dependence on robust CH\&S laws for compliance, which requires that clients do a lot. This is expected as adequate regulation of H\&S is based 
on robust laws. There was no consensus on the regulatory model. While the respondents expect third party involvement for example, the government, media, professional and industry bodies, their roles (except that of the government) mean that they will not have enforcement powers. There are indications of goal-based regulation but many NCSRCs and Non-SRCs do not agree with this but view that higher level of flexibility in the regulatory process would be beneficial to the contractors. Nevertheless, because of the inconsistencies in H\&S laws and standards, and regulatory processes, there are indications among the NCSRCs and stressed by few key informants that there is the need for a homogenous regulatory system for CH\&S.

\section{ANALYSIS AND DISCUSSION OF FINDINGS, AND DEVELOPMENT OF THE CH\&S REGULATION IMPROVEMENT STRATEGIES}

\section{The sample}

Architecture, construction and engineering projects are socio-technical and socioeconomic fields; the regulation of $\mathrm{CH} \& \mathrm{~S}$ then brings in the socio-legal dimension to the subject. Drawing on the profile of the respondents and organisations, it is evident that these areas are covered. Many of the respondents offer rich information because of the scope of their experiences. For example, some that draw on more than one point of experience include an 'Owner/Manager/Structural Engineer' of a small-sized contracting firm with 20 years of experience and has worked as a safety officer and civil engineer for a public sector firm and a private sector firm, respectively. According to Patton (1990), such respondents may be described as 'rich-information cases'. Consequently, it is logical to argue that the points of experience of the respondents are more than the 46 interviews that were used.

\section{Views of the respondents on the ways to improve $\mathrm{CH} \& S$ regulation}

In terms of monitoring and enforcement, the emphasis on this is understandable as it is pivotal in the regulatory process for improving compliance behaviour (Gracia Martinez et al. 2007; Umeokafor et al. 2014). However, the strategies make the difference, especially in a country that the regulation of H\&S is underperforming and criticised for the enforcement approach. The respondents' emphasis on inspection is questioned by Fairman and Yapp (2005) in that it has failed to reach expectations, there is no significant effect on the degree of compliance of Small and medium sized contractors. Analogously, May and Wood (2003) found that the more the inspection, the lower the level of compliance. There are also other regulatory implications such as weaker relationship between the regulator and the regulated. While based on this, it is tempting to debunk 'inspection' as the main regulatory strategy, the style of enforcement reported in May and Wood (2003) and that the location of the study is a developing country may explain inspection and enforcement record (May and Wood 2003). When the context of Nigeria is further examined, the rationale for the inspection and enforcement' as the main regulatory strategy becomes logical and seems pragmatic. For example, $H \& S$ is emerging in Nigeria, there is a culture of 'being forced to do things', and Manu et al. (2018) found that in terms of the 'carrot and stick' approach, the 'stick' approach seems prevalent in Cambodia, Vietnam and Malaysia. This is where reward and punishment is used to achieve compliance. If this is the case, it can be argued that there can be emphasis on inspection but this should be complemented with other strategies, for example, education and sensitisation. The main point here is that while enforcement is core, inspections should not be the sole and main tool used in monitoring compliance. 
The suggestion for an Independent National CH\&S Regulator (INCH\&SR) in Table 2 may appear naïve, but the points below show that it is promising and logical.

First, considering the complex nature of construction projects, the fragmented supply chain and the poorest levels of $H \& S$ practices of the industry when compared with other sectors, construction industry-focused regulator and H\&S programmes are needed.

Second, there is evidence that construction industry focused 'H\&S programmes have been successful. In particular, Manu et al. (2018) and Ministry Of Labour, Invalids and Social Affairs (MOLISA) (2013) show that DCs such as Vietnam have successfully implemented construction industry-focused programmes resulting in improved $\mathrm{H} \& \mathrm{~S}$. The activities of this programme are the establishment of a labour protection division and training activities that focus on construction activities (Manu et al. 2018).

Third, it can be argued that a dedicated regulator will focus the available resources solely on construction activities.

Fourth, independent regulators such Independent Corrupt Practices and Other Related Offences Commission (ICPC) have recorded 'debatable' success to some extent but not as expected.

Fifth, independent regulation is consistent with what happens in the oil and gas industry in Nigeria where the main legislation is Petroleum Act (Laws of the Federation of Nigeria (LFN)) 2004 (as amended) and the Mineral Oils (Safety) Regulations 1963 (as amended) overseen by the Minister of Petroleum. While the H\&S record of this industry is not without limited including poor records, it outperforms many industries in Nigeria (Umeokafor 2018). Also, in the UK, the Office Nuclear Regulation regulates safety and security in the nuclear industry. Of course, the contexts are different, for example, the level of hazards and the regulatory environments.

Sixth, there is evidence in the study to support the point in question. Authors (e.g. Aalders and Wilthagen 1997; Fairman and Yapp 2005), argue that one of the drivers of compliance and productive regulation is the involvement of the regulated in development of regulations because that creates the risk they are will know they can be controlled. If this is the case, it may be naïve to ignore the views of the regulated.

In the current study, alongside the suggested INCH\&SR, the respondents also suggest the supportive roles of other parties such as religious leaders, the media, and professional bodies (Table 2). This rationalises the homogenous regulatory system which should involve the INCH\&SR, the industry and social actors such as H\&S crusader (Table 2). The point here is to have an independent regulator that will focus on CH\&S but with the support of other third parties where the industry (oil and gas) will have controlled minimal powers to punish and the social actors no powers to punish. The oil and gas is specified because of their influence and contribution to SHE, as can be seen in the study. The involvement of other parties is consistent and 
underpinned by the Tripartism model of regulation elsewhere in this paper, but as will be seen later, the proposed model differs of which one difference is the proposition of the reflectivity concept of regulation. Hackitt's (2018) recommendations for regulating Fire Safety in High-Rise Buildings in England include a Joint Competent Authority involving the HSE, Local Authority Building Standards and fire and rescue authorities. One of the ways to get this H\&S regulation right is by reducing the level of fragmentation and parties in OHS regulatory processes (Abubakar 2016); this was considered in the proposed strategies. Full details are covered in the subsequent subsection.

However, the entire regulatory system should be transparent (Table 2), considering the level of corruption in Nigeria and the construction industry. The issue of corruption is reported in the enforcement of H\&S in Nigeria where the regulated gets away with poor H\&S practices due to bribery (Umeokafor et al. 2014). This is exacerbated by the high level of corruption in the construction industry globally (Teodorescu 2016) where a study by Chartered Institute of Building shows that $48 \%$ of the respondents view corruption as commonplace in the UK construction industry. Other possible social barriers that compound this include political influence. However, the respondents proffer solutions, for example, using the media and professional bodies to 'check' the activities of the INCH\&SR which may be complemented by the activities of Anticorruption 'watch dogs' such as the Economic and Financial Crimes Commission (EFCC) and ICPC. These institutions are empowered by law to 'fight' corrupt practices and fraud. To improve transparency, there should be a guideline or framework for the enforcement officers such as the enforcement management models that $H \& S$ recommends. This will guide the enforcement officers during enforcement to ensure consistency and transparency.

The negative implications of lack of adequate local H\&S laws are evident in this paper. Addressing this is pertinent in getting the traditional phase of H\&S culture evaluation right (Finneran and Gibb 2013). However, this must be based on the contexts of Nigeria, an area that if overlooked the improvement of H\&S will be farfetched (Umeokafor et al. 2018). This rationalises the contextualised construction H\&S laws in Table 2. This can be different from the Labour, Safety, Health and Welfare Bill (2012) yet to be signed into law or a secondary legislation from this. However, untill this bill is passed into law, the line of argument in this paper is for contextualised construction H\&S laws. Such laws will address some barriers to H\&S and its regulation, for example, inadequate H\&S policies (Diugwu et al 2012; Umeokafor et al. 2018), impracticable standards (Umeokafor et al. 2018) and multiple actors in H\&S regulation (Umeokafor 2018a).

Goal-based laws enable self-regulation hence flexibility, but the prescriptive laws are fixed. The latter is beneficial to the SCs, MCs and MiCs; Loosemore and Andonakis (2007) found that they prefer prescriptive laws. Others have already recommended this for SMEs because it improves the understanding of compliance among SMEs and is easy to implement (for example Fairman and Yapp 2005). Further, in prescriptive standards, the inexperienced contractors are clear on what to do, because prescriptive laws serves as a standard of reference (Kuo and Cojeen n.d.). But it can result in financial burden and be misunderstood to mean the sole means of compliance (cf. Kuo and Cojeen n.d.). It can limit innovation (Kuo and Cojeen n.d.). Nevertheless, there has been a shift from prescriptive standards to goal-based standards because of 
its positive characteristics. However, there is still a mixture of both prescriptive laws and goal-based standards in countries such as Australia (Loosemore and Andonakis 2007).

In the current study, there is no consensus on the nature of the legislation, goal-based or prescriptive, among the respondents (Table 2). Drawing on the preceding paragraph, there is a case for both types of standards. Further, as Nigeria is still at the traditional phase of the evolution of safety culture (and there is evidence of lack of awareness of H\&S including legislation (ILO 2017; also see elsewhere in this paper), the use of prescriptive standards seems attractive and promising, at least to some extent. The use of detailed guidance is an alternative (Kuo and Cojeen n.d.) especially as there are no OSH guidelines for the implementation of H\&S laws (ILO 2017), but may not be the best option considering the context of Nigeria. If a mixture of goalbased or prescriptive standards is to be used, the prescriptive aspects will be strategically used at limited places but replaced with goal-based standards in due course. However, to improve transparency and clarity, the legislation should mainly have absolute duties and not qualified duties. This is where qualified duties in legislation have terms such as 'so far as is reasonably practicable' and absolute duties have terms such as 'must'.

Moreover, some of the suggested contents of this proposed CH\&S law are questionable. For example, the mandatory use of $H \& S$ consultants for every project may result in higher financial cost to $\mathrm{H} \& \mathrm{~S}$ for some contractors and client who already struggle to comply with H\&S (Umeokafor 2018b) or use cost as an excuse for non-compliance (Windapo 2013). According to ILO (2017), there is an inadequate number of competent H\&S consultants in Nigeria, according, hence the risk of untrained persons taking on the role. However, it is possible that every project beyond a certain size, for example, three storey building will be, at least, overseen by a certified H\&S consultancy or practitioner firm, appointed by the client to work on their behalf but would not preclude the H\&S responsibilities of contractors.

Other suggestions such as statutory responsibilities for clients and designers are logical, workable and consistent with the requirements of legislation in other countries, for example the Construction Design and Management (CDM) Regulations 2015 in the UK (HSE 2015). Evidence from Nigeria shows that H\&S and other project indicators have improved because of client involvement in H\&S (Umeokafor 2018b). While clients are not committed to $H \& S$ and do not view it as important, the statutory backing with adequate enforcement is likely to improve the workability of the regulations (Umeokafor 2018b). Meanwhile, the level of statutory collaboration between the clients and contractors, as proposed by the respondents, may be impracticable or over-ambitious because some clients (including domestic client) may lack the skills and relevant knowledge in H\&S. Therefore, the strategy in CDM Regulations that enables domestic clients to pass their duties here to the contractors or the principal designer (HSE 2015) can be adopted in the contextualized H\&S laws. The respondents' view that a certain percentage of the contract sum should be located to $\mathrm{H} \& \mathrm{~S}$ is notable. However, there is a risk of corruption, over allocation to H\&S and bias against other project indicators. Nevertheless, this can be accommodated in the project cost. 
Manu et al. (2018) observe that education contributes to improving H\&S in DCs such as Vietnam. It is a core regulatory instrument (Fairman and Yapp 2005) and one of the measures to encourage or improve compliance in the compliance spectrum presented by Gemmell (2010) in Gemmell and Scott (2013). The compliance spectrum shows various types of compliance behaviours, from 'criminals' who do not comply with laws hence should be hit hard with punitive measures to 'champions' in compliance who should be rewarded. Between these two behavior types in the spectrum are other behavior types including the 'careless' regulatees hence should be educated and the 'confused' regulatees should be enabled to comply. These are consistent with the findings of the current study. For example, there is evidence that not all contractors comply with H\&S hence the analysis groups, CSRCs, NCSRCs and Non-SRCs. There is emphasis on education and sensitization in Table 2 and evidence that the contractors are confused and careless hence the cry for education to enable compliance with H\&S. This may be explained by the lack of OHS guidance for implementing H\&S laws that is lacking in the country (ILO 2017). Authors such as Diugwu et al. (2012) have also identified lack of awareness as a barrier to H\&S in the Nigerian construction industry. Importantly, the suggestions in terms of 'education and senstitsation' in Table 2 are logical, workable and fundamental. The grassroots approach to education and sensitisation is pragmatic and presents opportunities that should be exploited by other DCs. However, steps to ensure that the quality of any training and communication is not diluted as it goes down the supply chain, key barrier to H\&S improvement (Siew 2015). Also, there is the need to introduce a safety certification competence system (Zahoor et al. 2016) but the factors and the methods of assessing this need to consider the context-based and not coping what is done in developed countries such as UK.

Following this analysis and discussion, the draft of the strategies were evaluated by respondents; see methodology for details. The final strategies induced from the interviews are outlined below. According to authors such as Zahoor et al. (2016), such strategies may be generalised for other delevloping countries that share similar characteristics with Nigeria in terms of work environment and conomic conditions, for example, Ghana, Pakistian, Thailand and Bhutan. However, this should not preclude country specific studies.

\section{The CH\&S regulation improvement strategies}

1. Policymakers and government should provide CH\&S legislation that is based on the context of Nigeria and consultation with key regulatory parties, for example, the regulated, communities, social actors, industries such as oil and gas, trade associations and so forth. The legislation should cover the following:

A. H\&S duties assigned to clients from the early stages of construction to the decommissioning of the product. Domestic clients can shift the $\mathrm{H} \& \mathrm{~S}$ duties to principle designers or contractors but will be accountable.

B. Mandatory H\&S courses or modules, a condition for accreditation of programmes by Ministry of Education and professional bodies such as COREN.

C.Duties for designers to design for safety and contractors (including subcontractors) to construct safely. 
D.Competent H\&S personnel to oversee each construction project depending on the project size, at least the design for safety aspect of the project.

E. Mandatory allocation of funds for H\&S by clients, perhaps a percentage of the contract sum of the project.

F. Establishing a homogenous regulatory framework inspired by some aspects of 'Tripartism' and 'Reflexivity' but underpinned by goalbased legislation and prescriptive standards and/or detailed guidiance ; the prescriptive aspects will be strategically used at limited places but is replaced with goal-based standards in due course. Emphatically, the prescriptive standards will not be applicable to large complex projects to enable innovation rather goal-based legislation is recomended. The goal-based legislation should have mainly absolute duties and fewer qualified duties which, will involve an INCH\&SR to oversee the entire regulatory system including enforcing and monitoring compliance with the contextualized CH\&S laws, but supported by the the oil and gas industry (only when the construction projects take place there) and social actors such as H\&S crusaders. The social actors will not have any enforcement powers; they will act as whistle blowers, monitor the activities of INCH\&SR through ways such as requesting information from regulatory activities. The oil and gas industry will work 'hand-in-hand' with the INCH\&SR in the regulatory process but with clear responsibilities and scope; they can regulate some aspects of construction overseen by the INCH\&SR and in conformance and not below the requirement of the contextualised CH\&S laws. The oil and gas industry, contractors and INCH\&SR can implement a mixture of public and private sector legal and non-legal, strategies. By implication, there is 'reflectivity', covered in 'conceptual foundation' section. The goalbased legislation and all above will mean that the regulated, the client, contractors and subcontractors will have goal-based duties. This will consolidate flexible regulatory approach. There should be an enforcement management model or guide for enforcement officers to ensure transparency, consistency and proportional use of regulatory instruments.

G.Mandatory (online or in person) registration of all construction projects with the INCH\&SR before or, at least, two weeks after commencement of projects, and to inform them when the project is stopped for four weeks, and completed. This should cover the description of the project, estimated duration, address of the project, contractor or main contractor, and duty holders.

H.Duties on the INCH\&SR to provide and ensure accessible H\&S information to the public, free of charge.

I. Provisions for independent H\&S competency assessment bodies for contractors and subcontractors, with the outcome of level of competencies on a database that can be accessible to the public.

2. Policymakers should ensure that anti-corruption bodies, EFCC and ICPC, 'watchdog'the activities of the proposed INCH\&SR toward ensuring transparency in its regulatory activities. This can be done in many ways such as ensuring that the activities of the regulators are accessible by EFCC and 
ICPC through an active interactive electronic platform but INCH\&SR will not report to them.

3. The regulatory activities of INCH\&SR should include 'punishment' strategies (such as sanctions) and 'persuasion and cooperation' strategies (for example education and awareness, advise, adoption of incentives, negotiation).

4. The regulatory framework should accommodate the willingness and contribution of other parties such as communities to H\&S. This can be through involving them in the development of national policy, education and sensitisation programmes, and whistle blowing. The community leaders should be held accountable for any uncontrolled or illegal activities of members of their communities in the regulatory process.

5. Academics should update or (where absent) include H\&S in the curricula but most importantly integrate moral and cultural arguments for H\&S.

6. Through international bodies such as the International Labour Organisation, professional bodies should instigate external pressure on the government increase their attention and support for $\mathrm{H} \& \mathrm{~S}$.

\section{CONCLUSION}

Using Nigeria as a case, the study developed strategies for improving CH\&S regulation in a complex regulatory environment based on empirical evidence. Six main strategies and nine sub-strategies are presented including that the government and policymakers should establish a homogenous flexible CH\&S regulatory regime. H\&S legislation designed for the construction industry that adequately considers the social, political, technological, cultural, social and institutional environments of DCs such as Nigeria should enable this. The regulatory framework should be based on 'Tripartism' and 'Reflexivity' but underpinned by goal-based legislation (including absolute duties) and (in limited places) prescriptive legislation or adequate guidance. The prescriptive aspects should be strategically used at limited places but replaced with goal-based legislation in due course. Given the issues associated with prescriptive standards, an adequate case has been made in the paper for combining this with the goal-based standards. In the proposed regulatory system, the oil and gas industry and social actors will support a proposed Independent National CH\&S Regulator who will oversee the entire regulatory system. This will result in the adoption of a mixture of legal and non-legal, of public and private sector strategies. The proposed contextualised CH\&S laws should stipulate H\&S duties for clients, contractors and subcontractors. The regulatory strategies also focus on education and awareness by the proposed CH\&S regulator and other parties such as academics in the construction industry.

The practical implications of the study include that in improving CH\&S regulation in complex regulatory environments, education and awareness at industry and grassroots level should be a part of the critical regulatory strategies. Further, being the foundation for improving $\mathrm{CH} \& \mathrm{~S}$, the regulatory regime should be robust and supported with adequate construction laws that factor in the contexts of DCs including the contributions of non-state actors. Despite the evaluation of the strategies by the respondents for workability, they are subject to implementation. Further studies on how to educate and sensitize professionals on these strategies are recommended. Also, the study suggests hypotheses which further research can test. For example, the regulation of $\mathrm{CH} \& \mathrm{~S}$ would improve if an Independent National CH\&S Regulator 
oversees the entire regulatory system with the support of oil and gas industry and social actors; the transparency in the proposed CH\&S regulatory system would be improved if social third parties 'check' the activities of the INCH\&SR.

\section{ACKNOWLEDGEMENTS}

This paper forms part of an extensive study, a PhD study titled 'Realities of construction health and safety regulation in Nigeria', which has resulted in other publications.

\section{REFERENCES}

Aalders, M., and Wilthagen, T. (1997) Moving beyond command-and control: reflectivity in the regulation of occupational safety and health and the environment. Law and Policy, 19(4), 415-443.

Abubakar, .U. (2016) Structural and implementation issues around the new Nigerian Labour, Safety, Health And Welfare Bill (2012): Lessons From UK, USA, Australia And China. Transactions of the VŠB - Technical University of Ostrava, Safety Engineering Series, Vol. 11 (1), pp. 61-71.

Annan, J., Addai, E. K. and Tulashie, S. K. (2015) A Call for Action to Improve Occupational Health and Safety in Ghana and a Critical Look at the Existing Legal Requirement and Legislation. Safety and Health and Work, 6(2), pp146150.

Ayres, I. and Braithwaite, J. (1991) Tripartism: Regulatory Capture and Empowerment. Law and Social Inquiry 16, 435-496.

Brod, M., Tesler, L.E. and Christensen, T.L. (2009) Qualitative research and content validity: Developing best practices based on science and experience. Quality of Life Research, 18, 1263-1278.

Bartle, I. and Vass, P. (2005) Self-Regulation and the regulatory state - A survey of policy and practice. Centre for the Study of Regulated Industries, University of Bath. Research Report 17.

Braun, V. and Clarke, V. (2006) Using thematic analysis in psychology, Qualitative Research in Psychology, 3:2, 77-101

Bowen, G. A. (2008) Naturalistic inquiry and the saturation concept: a research note. Qualitative Research, 8(1), 137-152.

Castillo-Montoya, M. (2016) Preparing for Interview Research: The Interview Protocol Refinement Framework. The Qualitative Report, 21 (5) 811-831.

Creswell, J. W. and Miller, D. L. (2000) Determining validity in qualitative inquiry, Theory into Practice, 39(3), 124-130.

Diugwu I.A., Baba D. L., and Egila A. E. (2012) Effective regulation and level of awareness: An expose of the Nigeria's construction industry. Open Journal of Safety Science and Technology, 2012, (2), pp 140-146.

Guba, E. G. (1981). Criteria for assessing the trustworthiness of naturalistic inquiries. Educational Technology Research and Development 29:75-91.

Guba, E. G., and Lincoln, Y. (1989). Fourth generation evaluation. Newbury Park, CA: Sage.

Easterby-Smith, M., Thorpe, R. and Lowe, A. (1991) Management research: an introduction. Thousand oaks, CA. Sage publications. 
Erikkson, P. \& Kovalainen, A. (2008). Qualitative research in business research. Thousand Oaks, CA. Sage.

Fairman, R. and Yapp, C. (2005) Enforced self-regulation, prescription, and conceptions of compliance within small business: The impact of enforcement. Law and Policy, 27 (4), 491-519.

Fereday, J. and Muir-Cochrane, E. (2006) Demonstrating rigor using thematic analysis: A hybrid approach of inductive deductive coding and theme development. International Journal of Qualitative Methods 5(1) 1-11.

Finneran, A and Gibb, A. (2013) W099: Safety and Health in construction: Research Roadmap report for consultation. Retrieved on 05-08-2018 from https://dspace.lboro.ac.uk/dspace-jspui/bitstream/2134/12523/3/pub\%20376.pdf

Gemmell, C. (2010), "Politics and better environmental regulation", Conference Paper to the Annual Regulatory Affairs International Symposium, Institute for Parliamentary Affairs and Commonwealth Association, London, available at: http://regulationforum.org/docs/14-07-2010/08\%20Campbell\%20Gemmell.pdf

Gemmell, C. and Scott, M. 2013, 'Environmental regulation, sustainability and risk', Sustainability Accounting, Management and Policy Journal, 4, (2), 120-144

Gracia Martinez, M., Fearne, A., Caswell, J., and Henson, S., (2007) Co-regulation as a model for food safety governance: Opportunities for Public-Private Partnership. Food Policy (32) 299-314.

Gunningham, N. (2011) Investigation of industry self-regulation in workplace health and safety in New Zealand. Gunningham \& Associates Pty Ltd. Retrieved on $16-07-18$ from http://regnet.anu.edu.au/sites/default/files/publications/attachments/201504/NG_investigation-industry-self-regulation-whss-nz_0.pdf

Gunningham, N. and Rees, J. (1997) Industry Self-Regulation: An Institutional Perspective, Law \& Policy, Vol. 19, (4),

Health and Safety Executive (HSE) (2018) Workplace fatal injuries in Great Britain 2018. Retrieved on 10 July from http://www.hse.gov.uk/statistics/pdf/fatalinjuries.pdf

Health and safety executive (HSE) (2015), Managing health and safety in construction: Construction Design and Management, Retrieved on 06-07-18 from http://www.hse.gov.uk/pubns/priced/1153.pdf

Humble, A. M. (2009) Technique triangulation for validation in directed content analysis. International Journal of Qualitative Methods, 8(3), 34-51.

Idoro, G.I. (2011) Comparing occupational health and safety (OHS) management efforts and performance of Nigerian construction contractors. Journal of Construction in Developing Countries, 16(2), 151-173.

International Labour Organisation (ILO) (2017) Nigeria Country Profile on Occupational Safety and Health 2016. Retrieved on 27 August 2018 from https://www.ilo.org/wcmsp5/groups/public/---africa/---ro-addis_ababa/---iloabuja/documents/publication/wcms_552748.pdf

International Labour Orgaisation (ILO 2018) World Statistics. Retrieved on $11^{\text {th }}$ August 2018 from https://www.ilo.org/moscow/areas-of-work/occupationalsafety-and-health/WCMS 249278/lang--en/index.htm

Kuo, C. and Cojeen, P. H. (n.d.) Managing Ship Structural Development. Retrieved on 21 August 2018 from http://www.shipstructure.org/pdf/2000symp07.pdf

Lincoln, Y. S., and E. G. Guba. (1985). Naturalistic inquiry. SAGE, Newbury Park, California, USA. 
Loosemore, M. and Andonakis N. (2007) Barriers to implementing OHS reforms The experiences of small subcontractors in the Australian Construction Industry. International Journal of Project Management, 25 (6), 579-588

Manu, P., Mahamadu, A., Phung, V. M, Nguyen, T. T, Chandavid Ath, Heng, A. Y. T., and Kit,. S. C (2018) Health and safety management practices of contractors in South East Asia: A multi country study of Cambodia, Vietnam, and Malaysia. Vol.107, 188-201, https://doi.org/10.1016/j.ssci.2017.07.007

May, P. J., and Wood, R. S. (2003) At regulatory front Lines: Inspectors' enforcement styles and regulatory compliance. Journal of Public Administration Research and Theory, 3 (2) 117-139.

Mero-Jaffe, I. (2011) 'Is that what I said?' Interview transcript approval by participants: An aspect of ethics in qualitative research. International Journal of Qualitative Methods, 10(3), 231-247.

MOLISA (2012) National programme on occupational safety and occupational health in period of 2011-2015. MOLISA. Available https://www.ilo.org/wcmsp5/groups/public/---asia/---ro-bangkok/---srobangkok/documents/policy/wcms_186680.pdf (Accessed 14/08/2018).

Nowell, L. S., Norris, J. M., White, D. E., and Moules, N. J. (2017). Thematic Analysis: Striving to Meet the Trustworthiness Criteria. International Journal of Qualitative Methods 16: 1-13

Okoye, P. U. (2018) Occupational Health and Safety Risk Levels of Building Construction Trades in Nigeria. Construction Economics and Building, 18:2, pp. 92-109.

Omeife, C. A. and Windapo, O. A. (2013) The impact of national building code on professionalism. Proc.: 43rd Builders Conference/AGM, Abuja, Nigeria, 1-12.

Palys, T. (2008) Purposeful sampling. In L. M. Given (Ed.) The Sage Encyclopedia of Qualitative Research Methods. (Vol. 2). Sage: Los Angeles, 697-8.

Patton, M. (1990) Qualitative evaluation and research methods (169-186). Beverly Hills, CA: Sage.

Pybus, R (1996) Safety Management: Strategy and Practice. Oxford: Butterworth Heinemann.

Sands, R. G. and Roer-Strier, D. (2006) Using data triangulation of mother and daughter interviews to enhance research about families. Qualitative Social Work 5(2), 237-260.Health and Safety Executive (HSE) (2018) Workplace fatal injuries in Great Britain 2018. Retrieved on 10 July from http://www.hse.gov.uk/statistics/pdf/fatalinjuries.pdf

Saunders, M., Lewis, P. and Thornhill, A. (2009) Research methods for business students (5th edition), Prentice-Hall, London UK.

Scharrer A. and Bogus, S. M. (2011) The effect of partnership programs on improving safety in construction companies, Proc. CIB W099 International Health and Safety Conference, 24-26 August 2011, Washington, USA

Siew, R. Y. J. (2015). Health and safety communication strategy in a Malaysian construction company: A case study. International Journal of Construction Management, 15(4), 310-320. doi:10.1080/15623599.2015.1084469

Strauss and Corbin (1990) Basics of qualitative research: Grounded theory Procedures and Techniques. London: Sage.

Tadesse, S. and Israel, D. (2016) Occupational injuries among building construction workers in Addis Ababa, Ethiopia. Journal of Occupational Medicine and Toxicology (2016) 11:16 
Teodorescu, L. (2016), "Five years on: what impact has the bribery act had on construction?", Construction Manager, pp. 38-39.

Umeokafor, N. I. (2018a) Community interventions in construction health and safety and its implications: Evidence from Nigeria. Journal of Financial Management of Property and Construction, 23 (3), DOI: 10.1108/JFMPC-10-2017-0041.

Umeokafor, N. I. (2018b) An investigation into public and private client attitudes, commitment and impact on construction health and safety in Nigeria. Engineering, Construction and Architectural Management, 29(6), 798-815

Umeokafor, N. I., Windapo, A. O., and Manu, P. A. (2018) Country context-based opportunities for improving health and safety. In Saurin, T. A., Costa, D. B., Behm. M., and Emuze, F. (Eds.). Proc:. Joint CIBW99 and TG59 Conference, Salvador, 177-186

Umeokafor, N., Isaac, D., Jones, K., \& Umeadi, B. (2014). Enforcement of occupational safety and health regulations in Nigeria: A exploration. European Scientific Journal, 3, 92-103.

Walls, C. B. and Dryson, E. W. (2002) Failure after 5 years of self-regulation: a health and safety audit of New Zealand engineering companies carrying out welding. Occupational Medicine, Vol. 52(6), pp. 305-309.

Windapo, A (2013) 'Relationship between degree of risk, cost and level of compliance to occupational health and safety regulations in construction', Australasian Journal of Construction Economics and Building, 13 (2) 67-82

Zahoor, H., Chan, A. P. C., Masood, R., Choudhry, R. M., Javed, A. A., \& Utama, W. P. (2016). Occupational safety and health performance in the Pakistani construction industry: stakeholders' perspective. International Journal of Construction $\quad$ Management, $16(3), \quad$ 209-219. doi:10.1080/15623599.2015.1138027 